\title{
UMA ANÁLISE DA EXTINÇÃO DA CONSOLIDAÇÃO PROPORCIONAL EM INVESTIMENTOS JOINT VENTURES A PARTIR DA PERSPECTIVA DAS EMPRESAS QUE CONTRIBUÍRAM JUNTO AO IASB
}

Jocely Alves de Souza

jocely_souza@hotmail.com

Universidade Federal de Pernambuco

Márcia Ferreira Neves Tavares

marcia@ferreiraauditores.com.br

Universidade Federal da Paraíba

\author{
Luiz Carlos Marques dos Anjos \\ luiz@consultorcontabil.com \\ Universidade Federal de Alagoas \\ Christianne Calado Vieira de Melo Lopes \\ christiannecalado@yahoo.com.br \\ Universidade Federal de Pernambuco
}

Resumo: Esta pesquisa objetivou evidenciar os comentários mais abrangentes e técnicos recebidos pelo International Accounting Standards Board (IASB) referentes à proposta de eliminação da consolidação proporcional para os investimentos controlados em conjunto (joint ventures) e se estes foram acatados ou não na elaboração da norma final, a IFRS 11, promulgada pelo IASB. A pesquisa incluiu também a participação da única empresa brasileira (EDP Energia do Brasil S/A) que se manifestou sobre a questão perante a Comissão de Valores Mobiliários (CVM), em seu processo de audiência pública. A extinção da consolidação proporcional ocasionou mudanças diretas na análise das demonstrações contábeis das empresas, fazendo com que estudos acadêmicos nesse segmento tornem-se relevantes para a compreensão das atualizações contábeis e suas consequências para o mercado, contribuindo também com evidências sobre o processo político de construção e revisão de normas contábeis. A metodologia utilizada foi descritiva, com o método dedutivo, análise de conteúdo das cartas comentários, do documento base de Conclusão do IASB e utilizou-se do teste estatístico não paramétrico Qui Quadrado. Os principais resultados indicaram que a maior parte das empresas, que contribuíram com o IASB para o debate da extinção da consolidação proporcional, foram de origem europeia e, em sua grande maioria discordaram da eliminação da consolidação proporcional nos investimentos em joint ventures, argumentando que as demonstrações perderão o status de informação primária para os usuários da informação contábil, comprometendo assim a clareza das informações. Como conclusão, a pesquisa evidenciou que apesar de grandes discordâncias e fortes argumentos enviados pelas empresas, o IASB manteve o posicionamento de eliminação da consolidação proporcional, por meio da IFRS 11.

Palavras Chave: consolidação proporcional, método da equivalência patrimonial, IASB, IFRS 11, CPC 19.

Artigo recebido em: 14/04/2015; Aceito em: 13/10/2015

\section{INTRODUÇÃO}

Desde 2013, os investimentos em joint ventures (empresas em que o controle é compartilhado) passaram a ser contabilizados, pela empresa investidora, exclusivamente pelo método da equivalência patrimonial, em apenas uma linha na demonstração de resultados (receita ou despesa com equivalência patrimonial e em uma linha no balanço patrimonialinvestimentos). A norma anterior usada no Brasil, Instrução CVM nº 247 de 1996, determinava que estes investimentos fossem consolidados linha a linha no balanço da empresa 
investidora, com registro de receitas e despesas, ativo e passivo, de forma proporcional a fatia no capital total da investida.

A obrigatoriedade para as companhias abertas de consolidação proporcional para os investimentos em joint venture, está exigida pelo artigo 32 da Instrução CVM n 247 de março de 1996, porém desobrigado pela Deliberação CVM nº 694/12, a qual se encontra em conformidade com o CPC 19 (R2) - Negócios em Conjunto, correlacionados à IFRS 11.

Segundo Torres e Viri a existência de empreendimentos controlados em conjunto no Brasil é comum principalmente nos segmentos de energia elétrica, óleo e gás e imobiliário, o que torna as empresas destas áreas as mais suscetíveis a sofrer algum impacto. "As joint ventures costumam ser formadas em áreas em que é preciso investir muito para ter retorno, porque os dois sócios colocam dinheiros juntos" (TORRES, VIRI, 2013, P. 01).

Como houve modificação no critério de normatização para os investidores de joint venture, é relevante compreender a reação dos interessados nesta transição. O estudo busca evidenciar o posicionamento das empresas e a influência de suas opiniões nessa nova norma publicada pelos órgãos reguladores e normatizadores.

A partir de 2013, os números das joint ventures passaram a ser contabilizados exclusivamente pela empresa investidora pelo método da equivalência patrimonial e não mais pela Consolidação Proporcional, ocasionando as seguintes mudanças nos efeitos dos indicadores econômico-financeiros:

a) A rentabilidade sobre o patrimônio (lucro / patrimônio) permanece igual: Utilizando o método da equivalência patrimonial, o lucro é o mesmo e as receitas diminuem na mesma proporção em que os custos também diminuem, portanto a razão, ou seja, o resultado da operação aritmética permanece com o mesmo valor.

b) A margem líquida (lucro / receita) aumenta: como não há mais a junção (somatório) das receitas da investidora com as da investida em função da eliminação da consolidação, o valor da receita apresentada no balanço dos investidores é menor, consequentemente, quando é feita a divisão do lucro (o qual permanece o mesmo) pela receita, o resultado matemático que aparece é maior, aumentando as margens.

c) O endividamento (dívida / patrimônio) diminui - Também utilizando o Método da Equivalência Patrimonial, fazendo desta vez a divisão da dívida pelo patrimônio, o resultado obtido é um valor menor do que seria encontrado no caso da utilização da consolidação proporcional, em função de passivos menores quando da utilização exclusiva da Equivalência Patrimonial.

Torres (2013) chega a citar que as mudanças, decorrentes da eliminação da consolidação proporcional significam ativos e receitas menores para as companhias afetadas, embora o lucro e o patrimônio líquido permaneçam os mesmos. Quando calculado tendo como referência o patrimônio líquido, o endividamento das empresas tenderá a cair, já que o passivo diminui, e o patrimônio não. Mas em outro índice de endividamento usado no mercado, em que se mede a razão entre a dívida líquida e o EBITDA (Lucros antes de juros, impostos, depreciação e amortização), pode haver surpresas negativas. Isso porque a nova regra afeta todos os componentes dessa conta, a dívida bruta, a posição de caixa e o próprio EBITDA, uma vez que as receitas em controladas também não estão mais relacionadas no balanço da controladora. Pela equivalência, a diferença entre receitas e custos em controladas só aparece no Balanço Patrimonial na linha específica de resultado da equivalência patrimonial, não sendo evidenciado de forma individual tais receitas e custos.

De acordo com Magalhães (2013, apud Torres e Viri, 2013, p. 01): "É um efeito muito grande. Se tomarmos como base o balanço de 2011 deixaremos de consolidar $25 \%$ do EBITDA". Magalhães exemplifica que a Cemig (uma das maiores empresas do setor elétrico do país) ainda faz as contas para saber se haverá impacto em limites de endividamento previstos em contratos de dívida.

R. Cont. Ufba, Salvador-Ba, v. 9, n. 3, p. 18 - 34, set-dez 2015 
O exemplo acima mostra o quanto é importante saber em que essas empresas serão impactadas e qual suas opiniões quanto a esse processo de mudança nas demonstrações contábeis, já que o negócio da empresa continuará o mesmo, porém será necessário um esforço de comunicação com o mercado, para evitar análises subjetivas ligadas ao tamanho da empresa, tendo em vista que o Balanço Patrimonial mais enxuto afeta o efeito dos indicadores econômicos e financeiros.

Ainda em meio aos questionamentos dos gestores preocupados com a aceitação do mercado, se perguntando se não seria melhor permanecer consolidando do que apenas utilizar o MEP, o International Accounting Standards Board (IASB) emitiu uma norma para contabilização de joint arrangements, a IFRS 11, a qual entrou em vigor em janeiro de 2013, e o Brasil acompanhou a adoção de tal procedimento através na norma emitida pelo Comitê de Pronunciamentos Contábeis (CPC), CPC 19 (R2) - Negócios em Conjunto, aprovado pela CVM por meio da Deliberação CVM n 694/12, a qual ficou em audiência pública até o dia 22 de outubro de 2012.

Diante deste cenário, surge a questão problema direcionadora desta pesquisa: Qual o posicionamento do IASB diante dos principais comentários enviados pelas empresas, na formulação da norma referente à eliminação da consolidação proporcional e nos investimentos controlados em conjunto (joint ventures)? A pesquisa também contempla a participação do Brasil, a qual ficou restrita a uma carta enviada por empresa brasileira diretamente a CVM, em seu processo de audiência pública. Esta ampliação ocorre com o objetivo de compreender o posicionamento brasileiro em relação a esta temática.

A extinção da consolidação proporcional ocasiona mudanças diretas na análise das demonstrações contábeis das empresas, fazendo com que estudos acadêmicos nessa área tornem-se relevantes e colaborem para a compreensão das atualizações contábeis e suas consequências para o mercado, visto que a nova norma traz alterações consideráveis para o cenário contábil e principalmente para que os usuários tenham informações precisas sobre o que afeta seu patrimônio, portanto, faz-se necessário um estudo mais aprofundado sobre o tema. A ideia central da pesquisa é contribuir com evidências acerca do processo político na normatização contábil, assim como colaborar com o público em geral, que ainda está se adaptando à nova regra e busca amparo e/ou explicações para tal modificação identificando como ela impactará no futuro das instituições.

Este artigo procede como segue: Na seção 2 são discutidos os principais conceitos relacionados ao tema, na seção 3 apresenta-se a metodologia da pesquisa, em seguida são apresentados os resultados e por fim, as considerações finais do estudo.

\section{REFERENCIAL TEÓRICO}

\subsection{Significado de Lobbying}

O termo lobbying ainda é pouco empregado em estudos de normatização contábil no Brasil, com exceção dos trabalhos de Santos (2012), Carmo (2014) e Tavares, Anjos e Paulo (2014). Sutton (1984) afirma que as ações que as partes interessadas tomam para influenciar os normatizadores são coletivamente referidas como lobbying. Zeff ${ }^{1}$ (2012) porém, possui um conceito de lobbying mais contundente. Para ele, esse termo é usado para descrever "campanhas combinadas de ações contra uma proposta, onde os lobistas fazem ameaças ostensivas ou dissimuladas para solicitar intervenção para derrubar o padrão proposto ou,

\footnotetext{
${ }^{1}$ Political lobbying' goes beyond that, and the term is used here to describe concerted campaigns of action against a proposal, where the lobbyists make overt or covert threats to seek intervention to overturn a proposed standard or to compromise the standard-setter's reputation, independence, powers or even its existence.

R. Cont. Ufba, Salvador-Ba, v. 9, n. 3, p. 18 - 34, set-dez 2015
} 
comprometer a reputação de normatizadores, sua independência, poderes ou mesmo sua existência"(ZEFF, 2012, P.2, TRADUÇÃO LIVRE).

Apesar de a expressão lobbying soar de forma pejorativa, principalmente no Brasil onde não existe regulação desta atividade (ao contrário dos Estados Unidos da América e da União Europeia), Graziano (1996) afirma que fazer lobbying não é corrupção, sendo este "uma representação política de interesse em nome e em benefício de clientes identificáveis por intermédio de uma panóplia de esquemas que, em princípio, excluem a troca desonesta de favores"(GRAZIANO, 1996, P.4). Para o referido autor, o lobbying é um empreendimento caro e de resultados incertos, por isso não haveria necessidade de armar esquemas dispendiosos se houvesse disponibilidade de meios mais diretos e eficazes, como o procurado por esquemas de corrupção.

Logo, este artigo conceitua lobbying como uma prática institucionalizada, na qual os lobistas e suas organizações transferem conhecimentos especializados em suas áreas de atuação específicas, conhecimentos estes demandados pelos políticos. Por este conceito, o lobbying pode apresentar um lado positivo, quando o lobista busca transferir conhecimentos mais especializados aderentes a sua realidade cultural e local, apresentando aos políticos suas dificuldades em implementarem as diretrizes propostas. Além do que, o lobbying pode surgir em decorrência de divergência conceitual entre o lobista e o legislador e, dentro de um sistema democrático é natural que o lobista tenha direito a expressar suas opiniões e fundamentações. Corroborando com esta perspectiva, Ann Jorissen, Lybaert e Poel (2006), afirmam que o lobbying não é sempre negativo, pois indica a extensão de interesse sobre uma questão pelos constituintes, além de revelar informações sobre problemas de implementação potencial e custos das futuras normas, assegurando a legitimidade dos normatizadores e de suas normas. Assim como no estudo de Santos (2012) o lobbying, como empregado por este artigo, é limitado à manifestação explicita contida em cartas comentários submetidas em qualquer dos estágios do devido processo conduzido pelo IASB.

Como lembra Szuster (2011), a ocorrência de lobbying no processo de normatização contábil é cada vez mais intensa, tendo em vista a quantidade de promulgação de padrões emitidos e revisados para viabilizar a convergência internacional. Além do mais, alguns projetos normativos estão sendo elaborados de forma conjunta entre o IASB e o FASB, o que gera uma reação de grupos de interesses norte-americanos, com forte tradição de lobbying sobre o FASB e a Securities and Exchange Commission (SEC). Dessa forma, o cenário de convergência das normas contábeis fez com que, o lobbying antes de âmbito nacional, passasse a ter uma abrangência mundial, contemplando interesses de diversos agentes advindos de várias partes do mundo. Portanto, variáveis como tradições históricas no exercício de lobbying, fatores culturais e característica de mercado de capitais moldam o perfil dos grupos de interesses e delimitam países que apresentam uma maior probabilidade de influenciar os normatizadores.

Neste sentido, este paper alinha-se ao debate sobre o processo político de normatização contábil, identificando a reação das empresas na proposta de extinção da consolidação proporcional, levantando os argumentos de tais lobistas e o posicionamento do IASB ao final do processo.

\subsection{Due Process}

Através de consulta ao endereço eletrônico oficial das IFRS, tem-se a informação que as International Financial Reporting Standards (IFRS) são desenvolvidas por meio de um

R. Cont. Ufba, Salvador-Ba, v. 9, n. 3, p. 18 - 34, set-dez 2015 
processo de consulta internacional, que envolve indivíduos e organizações interessados de todo o mundo. Esse processo é composto de seis etapas, sendo estas:

1. Definição da agenda: O IASB desenvolve normas contábeis buscando atender melhor as necessidades dos usuários contábeis;

2. Planejamento do projeto: O IASB, através da sua equipe técnica, decide se irá realizar o projeto sozinho ou em conjunto com outro normatizador;

3. Elaboração e publicação de um documento de discussão (Discussion Paper): Apesar de um documento de discussão não ser obrigatório, o IASB normalmente publica esse documento para importantes tópicos a serem alterados, excluídos ou adicionados as normas, explicando o problema e solicitando os comentários iniciais dos constituintes;

4. Publicação de um projeto de exposição (Exposure Draft): Essa etapa é obrigatória no devido processo legal. Independentemente de o IASB haver publicado um documento de discussão, o projeto de exposição é o principal veículo para a consulta pública.

5. Desenvolvimento e publicação da IFRS: O desenvolvimento da IFRS é realizado durante reuniões do IASB. Em tais reuniões são considerados os comentários recebidos por parte dos constituintes, e quando estes logram sucesso de lobbying, as IFRS são alteradas para compatibilizar seus interesses; caso contrário o IASB permanece com sua proposta inicial;

6. Procedimentos após um IFRS ser emitido: O IASB realiza reuniões regulares com as partes interessadas, incluindo outros organismos de normatização, para auxiliar na compreensão das questões, imprevistos relacionados à aplicação prática e possíveis impactos de suas propostas. O Quadro 1 abaixo demonstra a cronologia de desenvolvimento das IFRS.

Quadro 1: Cronologia de desenvolvimento da IFRS.

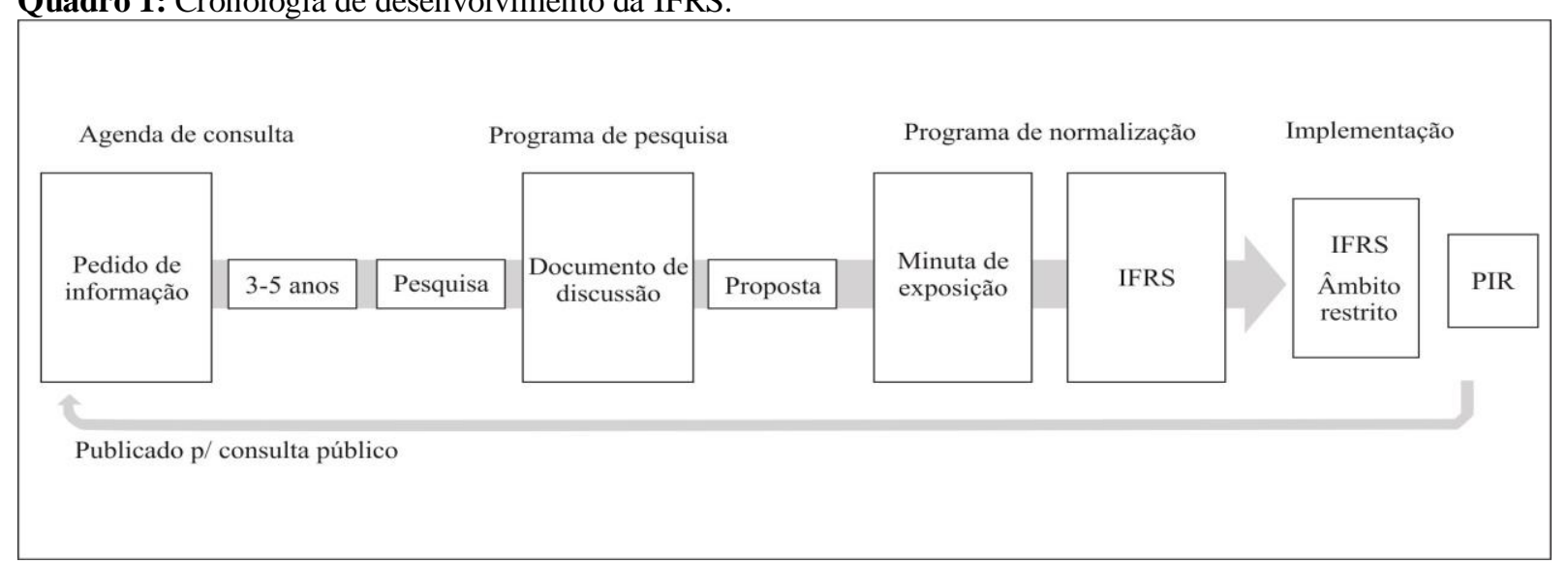

Fonte: IASB (2015).

Portanto, observa-se no Quadro 1 que desde da identificação, por parte do IASB quanto a necessidade de aprimoramento nas normas até sua efetiva alteração, criação ou exclusão, há um trâmite extenso e que busca assegurar que as melhores decisões serão tomadas e que essas mudanças efetivamente trarão benefícios aos usuários e clareza as demonstrações contábeis. A participação desses usuários através de comentários públicos formaliza-se por meio das Cartas Comentários, enviadas em diversas partes do processo, por entes físicos e jurídicos de todas as partes do planeta, nas quais eles expõem os mais variados motivos para concordar ou discordar da norma a ser implementada.

\subsection{Consolidação Proporcional X MEP}

A consolidação contábil é adotada em muitos países há anos, as exceções ficam por parte da África e alguns países do Oriente Médio, que não adotam as IFRS, consequentemente

R. Cont. Ufba, Salvador-Ba, v. 9, n. 3, p. 18 - 34, set-dez 2015 
não consolidam as demonstrações, segundo Assi (2012), com o objetivo de apresentar aos interessados nas informações contábeis os resultados das operações e a posição financeira da sociedade controladora e suas controladas, como se o grupo fosse uma única empresa que tivesse uma ou mais filiais ou divisões. As demonstrações financeiras consolidadas nos permite conhecer a real situação de um grupo de empresas que atuem no mercado sob um controle comum. Fica evidente que a consolidação contábil aglutina o patrimônio e os resultados de um conglomerado de empresas que tem o mesmo controle societário e administrativo, tendo como objetivo básico apresentar o patrimônio empresarial e o resultado do grupo de companhias distintas juridicamente, como se fosse uma só entidade econômica.

A consolidação proporcional lida com as contas patrimoniais (ativos e passivos) enquanto que o método da equivalência patrimonial (MEP) impacta nas contas de resultado (patrimônio líquido) e investimento. Anteriormente, as empresas podiam registrar a participação em joint ventures tanto por consolidação proporcional quanto por equivalência patrimonial, fundamentadas na Instrução da Comissão de Valores Mobiliários, $\mathrm{n}^{\circ} .247$ de 96. De acordo com pronunciamento CPC 19 (R2), a consolidação proporcional não será mais permitida.

O Método de Equivalência Patrimonial é um método contábil em que uma participação societária é inicialmente contabilizada pelo valor patrimonial e posteriormente ajustada pela mudança na participação do empreendedor nos ativos líquidos / patrimônio líquido da entidade sob controle, coligação ou controle conjunto.

Modesto (2008, p. 01) afirma: "Joint Venture ou empreendimento conjunto é uma associação de empresas, que pode ser definitiva ou não, com fins lucrativos, para explorar determinado(s) negócio(s) sem que nenhuma delas perca sua personalidade jurídica.”.

Sempre que a essas partes o acordo conferir direitos sobre os ativos líquidos desse negócio, estruturado por meio de um veículo separado (uma entidade legal separada), um empreendimento conjunto (joint venture) é caracterizado e, portanto, a equivalência patrimonial deve ser aplicada.

Torres e Viri (2013) falam ainda que o efeito da norma contábil- IFRS 11- sobre joint ventures é que em termos de lucro líquido e patrimônio líquido, nada muda. Mas as empresas vão parecer mais enxutas quando o analista olhar a receita e o total de ativos.

Ribeiro (2013) cita que, em prol da qualidade do relatório financeiro, o IASB decidiu extinguir a opção entre a consolidação proporcional e o MEP e impor apenas este último através da IFRS 11, de forma a permitir que as operações conjuntas e as joint ventures sejam analisadas numa base consistente, melhorando a compreensão e comparabilidade de tal relatório entre as diversas jurisdições, numa ótica de uniformidade de aplicação de políticas contábeis. No entanto, é reconhecido pelo próprio IASB (2011b) a complexidade da interpretação deste método, colocando dúvidas sobre as consequências da IFRS 11 em termos da utilidade da informação contábil produzida para o investidor.

\section{METODOLOGIA}

Trata-se de uma pesquisa descritiva, ou seja, descreve-se as características de uma população ou de um fenômeno. Segundo Gil (2008) uma das peculiaridades da pesquisa descritiva está na utilização de técnicas padronizadas de coleta de dados. O trabalho possui também características dedutivas, partindo do geral e seguindo ao específico. O método dedutivo é a modalidade de raciocínio lógico que faz uso da dedução para obter uma conclusão a respeito de determinada(s) premissa(s). Gil (2008) ainda fala que partindo de princípios reconhecidos como verdadeiros (premissa maior), o pesquisador estabelece relações com uma segunda proposição (premissa menor) para, a partir de raciocínio lógico, chegar à verdade daquilo que propõe (conclusão).

R. Cont. Ufba, Salvador-Ba, v. 9, n. 3, p. 18 - 34, set-dez 2015 
É uma pesquisa bibliográfica e documental, por meio da utilização de cartas comentários, as quais são a manifestação formal do lobbying de grupos de interesses perante o IASB. A pesquisa é desenvolvida a partir de fontes já elaboradas, como as cartas comentários, onde foram analisadas as respostas ao Exposure Draf 9 Joint Arrangements, exclusivamente sobre a questão 3: ${ }^{2}$ Você concorda que a consolidação proporcional deveria ser eliminada, levando em consideração que uma das partes reconheceria ativos, passivos, receitas e despesas se tivessem direitos e obrigações contratuais relativas a ativos e passivos individuais relativos a um acordo conjunto? Se não, por quê? (IASB, 2011, P. 3, TRADUÇÃO LIVRE).

O Quadro 2 descrito abaixo demonstra a população e a amostra do estudo, delimitado a estudar a participação das empresas no processo de contribuição ao IASB, incluindo também a única carta enviada a CVM durante a audiência pública realizada sobre a temática, totalizando uma amostra de 65 Cartas Comentários.

Quadro 2: Especificação da população e amostra do estudo.

\begin{tabular}{|c|c|c|c|c|}
\hline INSTITUIÇÃO & UNIVERSO & AMOSTRA & $\begin{array}{c}\text { \% DA } \\
\text { AMOSTRA }\end{array}$ & \multicolumn{1}{|c|}{ TIPO DE CONSTITUINTES } \\
\hline IASB & 115 & 64 & 55,6 & $\begin{array}{l}\text { EMPRESAS - Excluiu-se as pessoas físicas } \\
\text { e usuários contábeis (escritórios de } \\
\text { contabilidade, consultorias, auditorias). }\end{array}$ \\
\hline CVM & 01 & 01 & $100 \%$ & $\begin{array}{l}\text { EMPRESAS - Trabalhou-se com o total de } \\
\text { cartas recebidas pela CVM em seu processo } \\
\text { de audiência pública. }\end{array}$ \\
\hline
\end{tabular}

Fonte: Dados da pesquisa ( 2015).

Para a delimitação da amostra optou-se por analisar as cartas comentários das empresas, em função de representarem o grupo de maior volume de participações nesta questão específica, do que os demais grupos analisados separadamente.

As respostas das empresas a esta questão foram codificadas em Concorda / Discorda / Não se Posiciona. Os comentários foram comparados com o posicionamento final do IASB, em sua base para conclusão.

As Cartas Comentários acessadas são aquelas publicadas no site do IASB (IASB, 2014) e a disponibilizada em mídia pela CVM. Como em todo o Brasil foi enviada apenas uma carta à CVM, foi utilizada para complementação das informações a consulta o Relatório de Audiência Pública.

Para uma análise abrangente, é utilizado o teste estatístico Qui Quadrado. Conforme explica Conti (2009), o Qui Quadrado, simbolizado por $\chi 2$ é um teste de hipóteses que se destina a encontrar um valor da dispersão para duas variáveis nominais, avaliando a associação existente entre variáveis qualitativas. É um teste não paramétrico, ou seja, não depende dos parâmetros populacionais, como média e variância. $\mathrm{O}$ princípio básico deste método, ainda segundo Conti (2009), é comparar proporções, isto é, as possíveis divergências entre as frequências observadas e esperadas para certo evento.

Evidentemente, pode-se dizer que dois grupos se comportam de forma semelhante se as diferenças entre as frequências observadas e as esperadas em cada categoria forem muito pequenas, próximas a zero.

Utiliza-se também da análise de conteúdo, por meio da apresentação e análise dos argumentos convergentes pelas empresas que, como avalia Moraes (1999), é a constituição de uma metodologia de pesquisa usada para descrever e interpretar o conteúdo de toda classe de

\footnotetext{
2 "Question 3: Do you agree that proportionate consolidation should be eliminated, bearing in mind that a party would recognise assets, liabilities, income and expenses if it has contractual rights and obligations relating to individual assets and liabilities of a joint arrangement? If not, why?"
}

R. Cont. Ufba, Salvador-Ba, v. 9, n. 3, p. 18 - 34, set-dez 2015 
documentos e textos. Esta análise, conduzindo a descrições sistemáticas, qualitativas ou quantitativas, ajuda a reinterpretar as mensagens e a atingir uma compreensão de seus significados num nível que vai além de uma leitura comum. Para os fins pretendidos deste estudo, não foram definidas categorias qualitativas, focando-se na resposta objetiva das empresas acerca de uma única questão, identificando quais os argumentos mais citados por estas.

\section{RESULTADO DA PESQUISA}

\subsection{Resultado Descritivo}

Nesta seção são apresentadas as distribuições geográficas das empresas que enviaram as cartas comentários utilizadas na amostra, por região e países, com o objetivo de descrever a participação dos continentes perante a demanda do IASB sobre a extinção da consolidação proporcional.

Quadro 3: Total das Cartas Comentários por Continente.

\begin{tabular}{|l|c|r|}
\hline \multicolumn{1}{|c|}{ CONTINENTE } & QTDE & \multicolumn{1}{c|}{$\%$} \\
\hline ÁFRICA & 03 & $4,61 \%$ \\
\hline AMÉRICA DO NORTE & 10 & $15,40 \%$ \\
\hline AMÉRICA CENTRAL & 00 & $0,0 \%$ \\
\hline AMÉRICA DO SUL & 01 & $1,54 \%$ \\
\hline ÁSIA & 00 & $0,0 \%$ \\
\hline EUROPA & 47 & $72,30 \%$ \\
\hline OCEANIA & 04 & $6,15 \%$ \\
\hline Total de Cartas enviadas & 65 & $100 \%$ \\
\hline
\end{tabular}

Fonte: Dados da pesquisa ( 2015).

Verificando o Quadro 3, nota-se que a participação do continente africano representa $4,61 \%$ do total da amostra, ficando evidente a pouca preocupação deste continente em relação a esta questão.

Na América do Norte, o Canadá, país que possui grandes empresas de extração mineral, gás e petróleo, discorda da eliminação da consolidação proporcional, já os EUA têm uma opinião dividida.

A América Central demonstra não ter maiores interesses no assunto e não se posiciona a respeito, assim como a Ásia que apesar da economia emergente, não se pronunciou sobre pontos positivos ou negativos da questão.

Já na América do Sul, somente o Brasil envia correspondência, mesmo assim, em número mínimo (01 carta) e apenas para a CVM (não enviando cartas comentários ao IASB sobre esta questão). De forma discreta, não se posiciona claramente a favor ou contra a eliminação.

A Europa, precursora da convergência para demonstrações consolidadas, declarou-se na grande maioria dos países, ser contrária à extinção e a Oceania participa de forma discreta da pesquisa, mas ainda em maior número do que alguns outros continentes, porém seu posicionamento foi igualmente a favor e contra a eliminação da consolidação proporcional

R. Cont. Ufba, Salvador-Ba, v. 9, n. 3, p. 18 - 34, set-dez 2015 
para joint ventures, havendo um empate entre a concordância e a discordância. O Quadro 4 a seguir evidencia o posicionamento dos países europeus acerca da questão, em função deste continente ser o mais representativo da amostra deste estudo.

Quadro 4: Dados do Continente Europeu.

\begin{tabular}{|l|c|c|c|}
\hline \multicolumn{1}{|c|}{ PAIÍS } & Conc. & Disc. & NSP \\
\hline ALEMANHA & 02 & 04 & 03 \\
\hline BÉLGICA & 00 & 01 & 00 \\
\hline DINAMARCA & 00 & 01 & 00 \\
\hline ESPANHA & 00 & 04 & 00 \\
\hline FRANÇA & 03 & 07 & 01 \\
\hline GRÉCIA & 00 & 01 & 00 \\
\hline HOLANDA & 01 & 01 & 00 \\
\hline INGLATERRA & 02 & 05 & 01 \\
\hline ITÁLIA & 00 & 02 & 00 \\
\hline NORUEGA & 00 & 01 & 00 \\
\hline SUÉCIA & 00 & 01 & 00 \\
\hline SUÍ́ÇA & 02 & 03 & 01 \\
\hline TOTAL & 10 & 31 & 06 \\
\hline
\end{tabular}

Fonte: Dados da pesquisa (2015).

Pela análise dos Quadros 3 e 4, verifica-se que as empresas são em sua maioria originárias da Europa, estando países como França, Alemanha e Inglaterra entre os que mais enviaram Cartas Comentários, e os três discordam, em grande maioria, da extinção da consolidação proporcional para os investimentos em joint ventures.

Apenas no continente africano, através do único país remente e maior economia, a África do Sul, houve o apoio à eliminação da Consolidação Proporcional. A América do Sul não enviou carta ao IASB, mas enviou uma a CVM.

A relação entre continentes e posição quanto à eliminação da consolidação proporcional é apresentada no Quadro 5 a seguir.

Quadro 5: Posicionamento por Continente.

\begin{tabular}{|l|r|r|r|r|r|r|}
\multicolumn{1}{c|}{ CONTINENTE } & \multicolumn{2}{c|}{ CONCORDA } & \multicolumn{2}{c|}{ DISCORDA } & \multicolumn{2}{c|}{$\begin{array}{c}\text { NÃO SE } \\
\text { POSICIONA }\end{array}$} \\
\hline ÁFRICA & 03 & $4,61 \%$ & 00 & $0 \%$ & 00 & $0 \%$ \\
\hline AMÉRICA DO NORTE & 03 & $4,61 \%$ & 05 & $7,69 \%$ & 02 & $3,08 \%$ \\
\hline AMÉRICA CENTRAL & 00 & $0 \%$ & 00 & $0 \%$ & 00 & $0 \%$ \\
\hline AMÉRICA DO SUL & 00 & $0 \%$ & 00 & $0 \%$ & 01 & $1,54 \%$ \\
\hline ÁSIA & 00 & $0 \%$ & 00 & $0 \%$ & 00 & $0 \%$ \\
\hline EUROPA & 10 & $15,40 \%$ & 31 & $47,68 \%$ & 06 & $9,23 \%$ \\
\hline OCEANIA & 02 & $3,08 \%$ & 02 & $3,08 \%$ & 00 & $0 \%$ \\
\hline Total & $\mathbf{1 8}$ & $\mathbf{2 7 , 7 0 \%}$ & $\mathbf{3 8}$ & $\mathbf{5 8 , 4 5 \%}$ & $\mathbf{0 9}$ & $\mathbf{1 3 , 8 5 \%}$ \\
\hline
\end{tabular}

Fonte: Dados da pesquisa (2015).

O agrupamento feito no Quadro 5 constata que à exceção do continente africano, houve discordância quanto à extinção da Consolidação Proporcional em investimentos joint ventures

R. Cont. Ufba, Salvador-Ba, v. 9, n. 3, p. 18 - 34, set-dez 2015 
nos continentes, sendo bem evidente na Europa. Dos que se posicionam, os que discordam são um pouco mais do que o dobro dos que concordam.

Em função da representatividade do continente europeu em relação aos demais continentes, decidiu-se por realizar uma informação cruzada que confronte o posicionamento da Europa em relação aos demais continentes (aqui denominados resto do mundo). Após a exposição descritiva deste cruzamento, utiliza-se o teste estatístico não paramétrico Qui Quadrado, com o objetivo de identificar associação entre a opinião dos respondentes e suas respectivas regiões geográficas. Os resultados deste cruzamento e do teste $\chi^{2}$ são evidenciados no Quadro 6 abaixo:

Quadro 6: CONTINENTES * CONCORDÂNCIA Crosstabulation.

\begin{tabular}{|lll|r|r|r|}
\hline & & & \multicolumn{2}{|c|}{ CONCORDÂNCIA } & \\
\cline { 3 - 5 } & & & Concorda & Discorda & Total \\
\hline CONTINENTES & $\begin{array}{l}\text { Resto do } \\
\text { mundo }\end{array}$ & Count & 9 & 7 & 16 \\
& Europa & Count & $47,4 \%$ & $18,4 \%$ & $28,1 \%$ \\
& & $\%$ within CONCORDÂNCIA & $52,6 \%$ & $81,6 \%$ & $71,9 \%$ \\
& & Count & 19 & 31 \\
& & $\%$ within CONCORDÂNCIA & $100,0 \%$ & $100,0 \%$ & $100,0 \%$ \\
\hline
\end{tabular}

Fonte: SPSS 17 (2015).

Pela análise do Quadro 6 acima, constata-se que das empresas advindas do continente Europeu que se manifestaram favorável ou desfavoravelmente em relação à extinção, grande parte $(81,6 \%)$ discorda desta eliminação, preferindo manter a consolidação proporcional. Já em relação aos outros continentes, aquelas que se manifestam, preferem a eliminação da consolidação proporcional (47,4\% em relação ao total dos respondentes que concordam com a eliminação - isto é, dezenove empresas), porém, estes respondentes que concordam são apenas 33\% (sendo 19 empresas concordantes divididas por 57 empresas que se posicionam em relação a questão) do total de respondentes que se posicionaram.

Observando em números absolutos e de posse dos dados estudados até aqui, percebe-se que a diferença percentual se deve aos dados do continente Africano, pois sem as cartas daquele continente, há a preferência pela eliminação da consolidação proporcional em todos os continentes, em números percentuais, absolutos ou isolando caso a caso (Quadro 5).

A relação de associação entre as opiniões e os continentes é exposta no Quadro 7 abaixo:

Quadro 7: Qui Quadrado.

\begin{tabular}{|c|c|c|c|c|c|c|}
\hline & Valor & $\mathrm{df}$ & $\begin{array}{l}\text { Asymp. Sig. } \\
\text { (2-sided) }\end{array}$ & $\begin{array}{l}\text { Exact Sig. (2- } \\
\text { sided) }\end{array}$ & $\begin{array}{l}\text { Exact Sig. (1- } \\
\text { sided) }\end{array}$ & \begin{tabular}{|l} 
Ponto de \\
Probabilidade
\end{tabular} \\
\hline $\begin{array}{l}\text { Pearson Qui Quadrado } \\
\text { Teste de Fisher } \\
\mathrm{N}^{\circ} \text { de casos válidos }\end{array}$ & $\begin{array}{r}5,257^{\mathrm{a}} \\
57 \\
\end{array}$ & 1 & ,022 & $\begin{array}{l}, 031 \\
, 031\end{array}$ & $\begin{array}{l}, 025 \\
, 025\end{array}$ & \\
\hline
\end{tabular}

a. 0 células $(0 \%)$ tem expectativa de contagem inferior a 5. O mínimo esperado da contagem é 5,33.

b. Computado apenas para uma tabela $2 \times 2$.

c. A estatística padronizada é 2,273.

Fonte: SPSS17 ( 2015)

R. Cont. Ufba, Salvador-Ba, v. 9, n. 3, p. 18 - 34, set-dez 2015 
Pela análise do Quadro 7, constata-se que houve um ajuste no teste Qui Quadrado, por conta da contagem mínima esperada, sendo utilizado o teste exato de Fisher, o qual gerou o mesmo resultado de probabilidade. Por meio da relação desta probabilidade $(0,031)$ não se pode rejeitar a hipótese nula $\left(\mathrm{H}_{0}\right)$, indicando que existe relação associativa entre a opinião das empresas e o continente as quais estas pertencem. Este fato indica a existência de relação entre a predominância de opinião discordante e o continente Europeu, significando que as empresas com sede na Europa possuem uma tendência de discordar com a extinção da consolidação proporcional. Em função da representatividade da Europa na amostra deste estudo, infere-se que há maior opinião de discordância, pois mesmo havendo concordância de outras regiões geográficas, tais regiões não são representativas no total de respondentes.

A Europa, através da União Europeia, vem se modernizando contabilmente desde 2005 passando a partir dali a apostar em um sistema de informação financeira de nível mundial, o que chegou ao ápice na internacionalização das normas contábeis que ocorreu em 2010, e qualquer mudança significativa como a implementação da IFRS 11, por exemplo, é muito debatida e estudada, sendo, portanto esperado que seja a região geográfica que mais envie Cartas Comentários expondo os seus anseios e pontos de vista a respeito de itens importantes como contabilização de joint ventures.

O continente europeu iniciou a convergência para as demonstrações consolidadas, apesar de ainda publicar balanços individuais e consolidados (LIRA, 2010). Para as empresas europeias o balanço consolidado tem maior importância do que o individual, uma vez que essas instituições acreditam que um balanço mais compacto prejudica a compreensão da real situação financeira e econômica da empresa analisada, por isso a grande resistência à extinção da consolidação proporcional proposta.

\subsection{Análise de Conteúdo dos Resultados}

Fazendo uma análise da extinção da consolidação proporcional sob a perspectiva das empresas que contribuíram junto ao IASB e a CVM, dados interessantes puderam ser observados durante a leitura e classificação das cartas comentários enviadas.

Inicialmente tomando como base que o Brasil é a maior economia da América Latina (a segunda das Américas, atrás apenas dos Estados Unidos) e a sétima maior economia do mundo (ambos os dados são do Fundo Monetário Internacional - FMI em 2014), tem-se a expectativa de uma participação mais contundente na exposição de suas opiniões quanto às alterações de normas contábeis, porém, não é o que ocorre. O país restringiu-se a escrever, quanto à questão, uma única Carta Comentário a CVM e nenhuma ao IASB, na qual trata do assunto de forma genérica e não se posiciona efetivamente a favor ou contra a eliminação da consolidação proporcional, de qualquer modo, cita que as mudanças na norma causam alteração na forma de sociedade e isto se trata de um processo complexo devendo inclusive o prazo para entrar em vigor ser estendido para que as empresas possam se adequar. No mais, a Carta Comentário 01 da CVM referenciou o fato de que na essência o ativo e o passivo pertencem aos dois constituintes e fez a ressalva de que a norma parece voltar para a forma sobre a essência, já que prioriza a existência de um veículo separado como primeira regra de validação.

Já a União Europeia, região que explora fortemente a área de Petróleo e Gás, Energia e Telecomunicações, escreveu de forma numerosa ao IASB e ocorreu uma grande discordância do que a IFRS 11 propunha. Estas empresas discordam de demonstrações contábeis mais enxutas e creem que seus valores no mercado podem não ser bem compreendidos pelos interessados nas informações contábeis. Outra questão é que as empresas que enviaram as cartas, não estão propriamente interessadas tão somente nas melhorias ou dificuldades gerais que novas normas podem causar. Tais empresas preocupam-se primordialmente com o

R. Cont. Ufba, Salvador-Ba, v. 9, n. 3, p. 18 - 34, set-dez 2015 
impacto nos seus próprios Balanços Patrimoniais e Demonstrações de Resultado, independentemente de a regra ocasionar melhorias para os usuários da informação contábil.

A Carta Comentário 12, de um grande grupo europeu que trabalha na produção de Óleo, Gás e Indústria Petroquímica, externa bem a negativa desse segmento quanto à extinção da consolidação proporcional:

\begin{abstract}
${ }^{3}$ Não estamos de acordo com a afirmação. Nós não entendemos por que esse método deve agora ser proibido e não notamos no ED 9 qualquer argumento convincente para apoiar a afirmação de que o método de equivalência patrimonial é o único método mais adequado. O ED9 está prestes a criar discrepâncias sistemáticas e involuntárias entre principais demonstrações financeiras e notas financeiras. Por isso todas as informações relevantes serão exclusivamente divulgadas nas notas e as demonstrações financeiras primárias tenderão a tornar-se inútil. Isto parece inadequado e prejudicial para os usuários, pois as informações financeiras principais - sabemos por experiência que recebe mais atenção dos usuários (investidores, bancos, analistas...) - devem expressar a visão de conjunto mais concisa da performance de uma empresa. Além disso, todos os indicadores financeiros primários serão alterados, especialmente aqueles baseados em volume de negócios ou da dívida. Isto será particularmente perturbador para os usuários para uma comparação rápida e adequada entre as empresas. As empresas de comunicação estratégica e de negócios estarão, portanto, desconectadas das demonstrações financeiras primárias (Carta nº 12, TRADUÇÃO LIVRE).
\end{abstract}

Constata-se que as alegações dos constituintes são bem fundamentadas e percebe-se a preocupação com a representação dos dados e a interpretação que seus usuários podem fazer, tendo em vista que as organizações preferem dispor da consolidação proporcional para representar seus investimentos em controladas em conjunto, permitindo que as demonstrações contábeis sejam a fonte primária de informação econômica e de resultado da companhia.

A Carta Comentário 11, de uma multinacional alemã da área de produção de Petróleo e Gás, Construção Civil e Montagem de Máquinas, também apresenta discordância da eliminação da consolidação proporcional:

${ }^{4}$ Pensamos que o IASB deve reconsiderar a proposta de eliminar a consolidação proporcional por várias razões. Em nossa opinião, a consolidação proporcional pode

\footnotetext{
3 "We think that the IASB should reconsider the proposed elimination of proportionate consolidation for several reasons. In our opinion, the proportional consolidation might result in more meaningful information for many users as it best shows the benefits which the entity to and the risks arising from its operations better, regardless of their contractual rights and obligations. Based on the proportional accounting might lead to a better description of the economic substance of the arrangement. In this context, it has to be pointed out that many German entities carry out the bulk of their operations through joint ventures for the purpose of gaining market access in foreign countries, e. g. China. For those groups the elimination of proportionate consolidation would imply a considerable decrease in sales in their consolidated financial statements. Moreover, many of those groups use proportional consolidation for their managerial accounting for convergence purposes. An elimination therefore would lead to a divergence between the internal (management) and external accounting. For these reasons, we would suggest a review of the proposed changes."
}

4 "We think that the IASB should reconsider the proposed elimination of proportionate consolidation for several reasons. In our opinion, the proportional consolidation might result in more meaningful information for many users as it best shows the benefits which the entity to and the risks arising from its operations better, regardless of their contractual rights and obligations. Based on the proportional accounting might lead to a better description of the economic substance of the arrangement. In this context, it has to be pointed out that many German entities carry out the bulk of their operations through joint ventures for the purpose of gaining market access in foreign countries, e. g. China. For those groups the elimination of proportionate consolidation would imply a considerable decrease in sales in their consolidated financial statements. Moreover, many of those

R. Cont. Ufba, Salvador-Ba, v. 9, n. 3, p. 18 - 34, set-dez 2015 
resultar em informações mais significativas para muitos usuários, uma vez que melhor mostra os benefícios que a entidade tem direito e os riscos decorrentes de suas operações, independentemente de seus direitos e obrigações contratuais. Com base em que a contabilidade proporcional pode levar a uma melhor descrição da substância econômica do acordo. Neste contexto, deve-se salientar que muitas entidades alemãs realizam a maior parte de suas operações por meio de joint ventures com a finalidade de obter o acesso ao mercado em países estrangeiros, por exemplo, China. Para esses grupos, a eliminação da consolidação proporcional implicaria em uma diminuição considerável em vendas em suas demonstrações financeiras consolidadas. Além disso, muitos desses grupos usam consolidação proporcional para a sua gestão para fins de convergência. Uma eliminação, portanto, levaria a uma divergência entre a contabilidade interna (de gestão) e externa. Por essas razões, gostaríamos de sugerir uma revisão das mudanças propostas $\left(\right.$ Carta $\mathrm{n}^{\circ}$ 11 , tradução livre).

Este constituinte, além das questões gerais já alegadas por vários que enviaram Cartas Comentários quanto à compreensão dos dados das demonstrações contábeis, utilizou-se de constatações empíricas para fortalecer suas convicções, ao citar as experiências de grupo empresariais alemãs que realizam a maior parte de suas operações por meio de joint ventures para conseguir entrada em novos mercados, o que é um forte argumento.

Apesar dos argumentos da maioria das empresas que possuem joint venture nos mais diversos segmentos, alegando não concordarem com a extinção da consolidação proporcional, a IFRS 11 foi implementada, sob o argumento do IASB de que as mudanças foram realizadas no intuito de facilitar a adoção dos novos pronunciamentos.

\subsection{Análise da Base de Conclusão do IASB}

O IASB (2012), através da base de conclusão do Exposure Draft 9 (ED 9) expôs suas razões para eliminação da consolidação proporcional em joint ventures. O órgão normatizador alega que as propostas do projeto de exposição estão preocupadas principalmente em remediar aspectos da norma anterior que regulamentava a matéria (IAS 31) que são considerados um impedimento para a comunicação de alta qualidade sobre controle conjunto. $\mathrm{O}$ fato de a entidade poder escolher o tratamento contábil dado as suas demonstrações em joint ventures é o principal deles, pois considera que a possibilidade de haver opção entre a utilização da consolidação proporcional e método da equivalência patrimonial, pode levar a transações similares sendo contabilizadas de maneiras diferentes e consequentemente prejudicando a comparabilidade.

O IASB argumenta também ter concluído que a consolidação proporcional não é um método apropriado de contabilização para entidades controladas em conjunto. Diz que reconhecendo um número proporcional de cada ativo e passivo de uma entidade falta coerência com a definição de ativos em termos de controle exclusivo e passivos em termos de obrigações presentes, levando ao reconhecimento de valores que não representam fielmente uma entidade de ativos e passivos. Por exemplo, ele pode levar um empreendedor a reconhecer saldos de caixa que não tem a capacidade de dirigir e a partir do qual não se pode obter benefícios, sem consulta de outras partes, ou seja, a consolidação proporcional pode gerar informações semelhantes ao reconhecimento de direitos e obrigações contratuais, mas isso é por direito e não por fato.

groups use proportional consolidation for their managerial accounting for convergence purposes. An elimination therefore would lead to a divergence between the internal (management) and external accounting. For these reasons, we would suggest a review of the proposed changes."

R. Cont. Ufba, Salvador-Ba, v. 9, n. 3, p. 18 - 34, set-dez 2015 
Ainda em alusão ao registro nas demonstrações da posição financeira, o órgão normatizador ratifica o que foi citado anteriormente e explica que a proporção de cada ativo e passivo das entidades controladas em conjunto é caracterizada quando usada à consolidação proporcional, no entanto, não é possível distinguir quais os ativos que a entidade controla e tem a capacidade de administrar propriamente, sem precisar acordar com as demais partes.

Em conclusão, o IASB garante que as mudanças destinam-se a beneficiar os relatórios financeiros de três maneiras. Em primeiro lugar, uma entidade passa a ser obrigada a reconhecer apenas os ativos que controla e os passivos que são obrigações presentes. Em segundo lugar, a remoção de um tratamento contábil opcional melhora a comparabilidade. E por fim, alcança a convergência em princípio com o US GAAP (em português significa Princípios de Contabilidade Geralmente Aceitos nos EUA), que geralmente exige o uso do método da equivalência patrimonial para contabilizar as joint ventures. O IASB acredita que esses benefícios excedem os custos de implementação.

Em avaliação sobre as alegações dos constituintes e do IASB, percebe-se que ambos almejam clareza e confiabilidade nas demonstrações contábeis, porém, as instituições temem aparentar riqueza menor com as mudanças que foram realizadas com a homologação da IFRS 11. Havia também a comodidade de utilizar o método que a empresa achasse que melhor representava sua situação financeira e a eliminação da consolidação proporcional em joint venture e a obrigatória utilização do método da equivalência patrimonial inviabilizou essa prática.

\section{CONSIDERAÇÕES FINAIS}

O IASB recebeu ampla colaboração, predominantemente do Continente Europeu e a CVM recebeu apenas uma carta, remetida por uma empresa brasileira e que não se posicionou claramente a favor ou contra a extinção. A adoção do método da equivalência patrimonial como único método para a contabilização dos investimentos controlados em conjunto, provoca alterações nas demonstrações contábeis tornando-as mais compactas, existe alteração também nos indicadores de margem líquida e endividamento, e estes pontos são tidos como positivos para algumas empresas e negativos para outras, conforme o entendimento e interesse destas.

Os resultados da pesquisa mostram que a IFRS 11 foi implementada apesar de a maioria dos constituintes que enviaram Cartas Comentários e possuem investimentos em joint venture não concordarem com a extinção da Consolidação Proporcional e a utilização exclusiva do Método da Equivalência Patrimonial para contabilização deste tipo de investimento. Mesmo diante do número expressivo de empresas que enviaram suas opiniões e sugestões por utilizarem a contabilização em joint venture para gerir seus negócios, seus argumentos não influenciaram na formulação da norma.

Note-se que o resultado desta pesquisa abre espaço para a confecção de uma nova com os demais usuários da contabilidade que enviaram Cartas Comentários, mas não estão dentro do padrão da amostra pesquisada neste trabalho, representando cinquenta e uma cartas não analisadas de diversos constituintes como firmas de contabilidade, auditoria e usuários pessoas físicas.

Das 65 cartas analisadas, 39 discordaram da eliminação da consolidação proporcional em joint venture, um percentual de 58,52\%, sendo o equivalente a $33 \%$ do universo de cartas (116) e como ainda assim a IFRS 11 foi adotada, deve haver argumentos convincentes nos demais grupos de usuários contábeis, que podem ter influenciado o IASB na confecção da norma final. Esse trabalho não tem o intuito de exaurir o assunto, mas sim, deixar sua parcela de contribuição científica e trazer esclarecimentos que mostram novas possibilidades de pesquisa. Portanto, contribui com a academia ao demonstrar o posicionamento das empresas

R. Cont. Ufba, Salvador-Ba, v. 9, n. 3, p. 18 - 34, set-dez 2015 
quanto a esta questão, os principais argumentos de discordância inseridos e a posição final do IASB, no documento base para conclusão. Pesquisas deste tipo mostram-se interessantes por demonstrar o processo de normatização contábil em sua origem, apresentando evidências dos continentes que mais contribuem e quais as razões inseridas pelo Board para realizar alterações normativas. Logo, este estudo avança em relação a outras pesquisas que focam somente no impacto das normas internacionais, mas, não discutem o processo político existente na promulgação e revisão de normas internacionais de contabilidade.

\section{REFERÊNCIAS}

ANN, Jorissen. NADINE, Lybaert. and K. V. de P. Lobbying Towards a Global Standard Setter - Do National Characteristics Matter? An Analysis of the Comment Letters Written to the IASB. In: GREGORIOU N, G. AND M. G. (Ed.). Standards , Regulations and Financial Reporting. First edit ed. Burlington, MA: Elsevier, 2006. p. 1-617.

ASSI, Marcos. Quem adota as IFRS? Disponível em: <http://www.marcosassi.com.br/quem-adota-as-ifrs>. Acessado em: 04/11/2014 às 17:35h.

CARMO, C. H. S. DO. Lobbying na Regulação Contábil internacional: uma análise do processo de elaboração da norma sobre reconhecimento de receitas. [Tese de Doutorado] Universidade de São Paulo, 2014.

CARTA COMENTÁRIO No 11 (Freudenberg \& Co). Disponível em: $<$ http://www.ifrs.org/Current-Projects/IASB-Projects/Joint-Ventures/ED/Comments/Docume nts/CL11.pdf>. Acessado em: 18/07/2014 às 14:00h.

CARTA COMENTÁRIO No 12 (Technip). Disponível em: <http://www.ifrs.org/CurrentProjects/IASB-Projects/Joint-Ventures/ED/Comments/Documents/CL12.pdf>. Acessado em: 18/07/2014 às 14:20h.

CARTA COMENTÁRIO No 01 CVM (EDP Energia do Brasil S/A). Enviada a Comissão de Valores Mobiliários <www.cvm.gov.br>. Acessado em: 18/07/2014 às 15:00h.

COMISSÃO DE VALORES MOBILIÁRIOS (1996). Instrução CVM no 247, 27/03/96. Disponível em: < http://www.cnb.org.br/CNBV/instrucoes/ins247-1996.htm>. Acessado em: 18/07/2014 às 17:55h.

COMISSÃO DE VALORES MOBILIÁRIOS (2012). Instrução CVM no 694, 23/11/12. Disponível em: < http://www.cvm.gov.br/port/infos/Comunicado\%20Deli694.asp >. Acessado em: 18/07/2014 às 17:56h.

COMITÊ DE PRONUNCIAMENTOS CONTÁBEIS. PRONUNCIAMENTO $\begin{array}{lllllll}\text { TÉCNICO } & \text { CPC } & 19 & \text { (R2) } & \text { Disponível em: }\end{array}$ http://static.cpc.mediagroup.com.br/Documentos/274_CPC_19_\%20R2_rev\%2003.pdf >. Acessado em: 17/10/2014 às 10:10h.

CONTI, Fátima. Qui Quadrado. Disponível em: < http://www.ufpa.br/dicas/biome/biopdf/bioqui.pdf >. Acessado em: 25/11/2014 às 20:25h.

R. Cont. Ufba, Salvador-Ba, v. 9, n. 3, p. 18 - 34, set-dez 2015 
GIL, Antônio Carlos. Como elaborar projetos de pesquisa. $4^{\mathrm{a}}$ Ed. São Paulo. Atlas, 2008.

GRAZIANO, L. O Lobby e o Interesse Público. Revista Brasileira de Ciências Sociais, v. 12, n. 35, p. 1-12, 1996.

IASB (International Accounting Standards Board) (2011b), International Financial Reporting Standard, IFRS 11 - Joint Arrangements.

IASB (International Accounting Standards Board) Basis for Conclusions ED9. Disponível em: < http://www.ifrs.org/Current-Projects/IASB-Projects/Joint-Ventures/ED/Documents /BasisCED9.pdf >. Acessado em: 02/01/2014 às 12:00h.

IASB (International Accounting Standards Board) Comment Letters. Disponível em: $<$ http://www.ifrs.org/Current-Projects/IASB-Projects/Joint-Ventures/ED/Comments/Pages/Co mment-Letters.aspx>. Acessado em 15/10/2014 às 13:00h.

IASB, International Accounting Standards Board. How we develop IFRSs. Disponível em: <http://www.ifrs.org/How-we-develop-standards/Pages/How-we-develop-standards.aspx>.

Acessado em: 29 set. 2015

LIRA \& ASSOCIADOS ADVOCACIA. Migração para normas internacionais ocorre em vários países. Disponível em: < http://www.liraa.com.br/conteudo/1064/migracao-paranorma-internacional-ocorre-em-varios-paises >. Acessado em: 05/01/2015 às 08:30h.

MODESTO, José Antônio. Blogger: Joint Venture - definição. Disponível em: < http://joseantoniomodesto.blogspot.com.br/2008/10/joint-venture-definio.html >. Acessado em: 24/09/2014 às 17:15h.

MORAES, Roque. Análise de conteúdo. Disponível em: < http://cliente.argo.com.br/ mgos/analise_de_conteudo_moraes.html >. Acessado em: 25/11/2014 às 18:50h.

RIBEIRO, Maria do Céu Fernandes. Método de Equivalência Patrimonial na Consolidação das Joint Ventures - Uma Análise Prospetiva a partir do Caso Canadiano. Porto, Portugal, 2013. Disponível em: < http://sigarra.up.pt/fep/pt/publs_pesquisa .show_publ_file?pct_gdoc_id=63466 >. Acessado em: 01/10/2014 às 17:15h.

SANTOS, O. M. dos. Lobbying na Regulação Contábil e Qualidade da Informação: Evidências do setor Petrolífero. [Tese de Doutorado] Universidade de São Paulo - USP, 2012.

SZUSTER, F. R. Uma análise do valor social considerado pelo Comitê de Pronunciamentos Contábeis à luz da Teoria Tridimensional do Direito. [Tese de Doutorado] Escola Brasileira de Administração Pública e de Empresas, 2011.

TAVARES, M. F. N. ANJOS, L. C. M. PAULO, Edilson. Contribuições enviadas ao IASB/FASB referentes à revisão do draft de reconhecimento de receitas. Contextus Revista Contemporânea de Economia e Gestão, v. 12, p. 35-63, 2014. 
TORRES, Fernando. VIRI. Natália. Federação Nacional das Empresas de Serviços Contábeis e das Empresas de Assessoramento, Perícias, Informações e Pesquisas Fenacon. Norma para joint ventures reduzirá ativos e receitas. Disponível em: < http://www.fenacon.org.br/noticias-completas/458 >. Acessado em: 20/10/2014 às 17:40h.

TORRES, Fernando. Revista Valor Econômico. Disponível em: < http://www.valor.com.br/empresas/2733882/iasb-facilita-adocao-de-nova-regra-contabil-parajoint-ventures >. Acessado em: 23/12/2014 às 17:20h.

ZEFF, S. A. Political lobbying on Accounting Standards - US, UK and international experience. In: PEARSON (Ed.). Comparative International Accounting. 12. ed. Chicago: Pearson, 2012. p. 624. 